\title{
Early onset pre-eclampsia: recognition of underlying renal disease
}

\author{
B U IHLE, P LONG, J OATS
}

\begin{abstract}
A follow up study of 84 patients with early onset pre-eclampsia (before 37 weeks' gestation) showed a high prevalence of underlying renal disease. Renal abnormalities were found in 33 of the 49 primiparas (67\%) and in 22 of the 35 multiparas (63\%). Two thirds of the multiparas with pre-eclampsia before 37 weeks with a diagnosis of either essential hypertension or renal disease had recurrent pre-eclampsia. Maternal morbidity and fetal mortality were greater in the group with early onset pre-eclampsia than in a group with late onset disease. Idiopathic pre-eclampsia occurred in $10 \%$ of primiparas in the early onset group, whereas it was the main condition in over three quarters of primiparas in the late onset group.

A presumptive diagnosis of idiopathic pre-eclampsia is likely to be correct only in primiparas who develop the disease after 37 weeks of pregnancy; in all other cases careful search will almost certainly detect an underlying abnormality, predominantly renal.
\end{abstract}

\section{Introduction}

Pre-eclampsia is a syndrome of two distinct disease types; it may be purely idiopathic, restricted to and caused by pregnancy, or it may be due to an underlying hypertensive disorder. Chronic renal disease has long been recognised as an important precursor of pre-eclampsia. Nevertheless, its prevalence in pre-eclampsia is uncertain as it may be difficult to detect clinically and there is natural reluctance to perform biopsy for definitive diagnosis. In 1982 Fairley and Birch showed that finding dysmorphic "glomerular" erythrocytes in the urine is a highly specific (93\%) and sensitive $(99 \%)$ indicator of glomerulonephritis. ${ }^{1}$ This simple

\footnotetext{
Mercy Maternity Hospital and Department of Obstetrics and Gynaecology, University of Melbourne, Victoria, Australia

B U IHLE, FRACP, FACP, consultant physician

P LONG, FRCOG, FRACOG, obstetrician and gynaecologist

J OATS, MRCOG, FRACOG, first assistant, university department of obstetrics and gynaecology

Correspondence to: Dr B U Ihle, Department of Nephrology, The Royal Melbourne Hospital, Parkville 3050, Victoria, Australia.
}

screening test using phase contrast microscopy has given the opportunity to examine anew the association between chronic renal disease and pre-eclampsia.

We present a preliminary report of the findings of a special clinic established at the Mercy Maternity Hospital, Melbourne, for the follow up investigation of patients with pre-eclampsia.

\section{Patients and methods}

Patients referred to the follow up clinic include particularly those with early onset (before 37 weeks of gestation) pre-eclampsia and those with severe or recurrent pre-eclampsia of later pregnancy. Over 18 months 84 women with early onset and 94 with late onset pre-eclampsia attended the clinic and are the subjects of this study. These patients accounted for roughly half of all patients delivered at the hospital during the period with early onset pre-eclampsia. The remaining patients either were not referred to the clinic or were unable to return for three separate visits owing to domestic commitments or geographical difficulties.

Pre-eclampsia was diagnosed after 20 weeks of gestation by the presence of at least two of the following: blood pressure $140 / 90 \mathrm{~mm} \mathrm{Hg}$ or higher on two or more occasions, generalised oedema, and proteinuria without evidence of contamination or urinary infection. At this hospital the prevalence of preeclampsia is $10 \%$; a quarter of the cases are diagnosed before 37 weeks of gestation, so that the incidence of early onset pre-eclampsia is $2.5 \%$ of all deliveries.

At least two 24 hour estimations of creatinine clearance and total urinary protein were performed together with measurements of serum electrolyte and plasma urea and creatinine concentrations in the postpartum period. Phase contrast microscopy was used to detect glomerular haematuria in three separate midstream specimens of urine from each patient. Renal biopsy was done if the glomerular erythrocyte count exceeded $20 \times 10^{6} / 1$ (normal $\left.8 \times 10^{6} / 1\right)$ six weeks or more after delivery, biopsy being delayed until at least six months post partum to allow the morphological changes due to pre-eclampsia to subside. Biopsy specimens were processed for light, immunofluorescence, and electron microscopy. All patients with abnormal findings on urine microscopy had intravenous pyelography. Intravenous pyelograms were also obtained from patients whose urinary findings were normal but in whom there was clinical suspicion of underlying renal tract disorder-for example, a history of enuresis, recurrent urinary tract infection, or family history of polycystic kidney disease.

Essential hypertension was diagnosed when the findings from phase contrast microscopy and pyelography were normal and blood pressure was raised before 20 weeks of gestation or between pregnancies or persisted for at least three months after delivery.

Results were analysed according to parity, time of onset and severity of pre-eclampsia, and the prevalence of underlying disease. 


\section{Results}

In this series pre-eclampsia occurring before 37 weeks of gestation (range 24-36 weeks) was a more severe disease than that occurring after 37 weeks (range 37-42 weeks) (table I). In addition, placental dysfunction (subnormal oestriol excretion), low birth weight, and perinatal death were all significantly more common in the early onset group (table I).

TABLE I-Severity of pre-eclampsia and perinatal outcome by time of onset of pre-eclampsia. Except where stated otherwise figures are numbers (percentages) of cases

\begin{tabular}{|c|c|c|}
\hline & $\begin{array}{c}\text { Onset before } \\
37 \text { weeks } \\
(n=84)\end{array}$ & $\begin{array}{c}\text { Onset after } \\
37 \text { weeks } \\
(\mathrm{n}=94)\end{array}$ \\
\hline $\begin{array}{l}\text { Mean (SD) gestation at delivery (weeks) } \\
\text { Diastolic blood pressure }>100 \mathrm{~mm} \mathrm{Hg} \\
\text { Proteinuria }>0.3 \mathrm{~g} / \text { day } \\
\text { Deterioration in renal function } \dagger \\
\text { Coagulopathy } \\
\text { Low oestriol excretion } \\
\text { Low birth weight below } 10 \text { th percentiles } \\
\text { Perinatal mortality }\end{array}$ & $\begin{array}{l}33 \cdot 0(3 \cdot 2) \\
51(61) \\
37(44) \\
8(10) \\
30(36) \\
21(40) \ddagger \\
11(13) \\
15(18)\end{array}$ & $\begin{array}{l}39 \cdot 3(1 \cdot 3) \\
17(18)^{\star \star} \\
14(15)^{\star \star} \\
3(3) \mathrm{NS} \\
9(8)^{\star \star} \\
11(12)^{\star} \\
3(3)^{\star} \\
1(1)^{\star \star}\end{array}$ \\
\hline
\end{tabular}

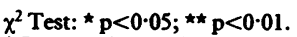

$f$ Increase in creatinine concentration $>30 \mu \mathrm{mol} / /(0.3 \mathrm{mg} / 100 \mathrm{ml})$ compared with baseline post partum.

tOestriol excretion measured in 52 cases only.

S Based on birth weight for period of gestation.

Chronic renal disease or essential hypertension was diagnosed in $76(90 \%)$ of the women with early onset pre-eclampsia ( 44 of the 49 primiparas, 32 of the 35 multiparas) (table II). In the late onset group over three quarters of the primiparas (57 of 73) were considered to have idiopathic or pregnancy induced pre-eclampsia, 11 (15\%) being found to have chronic renal disease; by contrast, $17(81 \%)$ of the multiparas in this group had an associated causal disease. these patients had normal renal function six weeks after delivery but five with IgA glomerulonephritis remained hypertensive.

Two primiparas were found to have systemic lupus erythematosus (revised American Rheumatism Association criteria); one multipara was known to have had this disease for one year before the index pregnancy and renal biopsy showed focal necrotising glomerulonephritis consistent with the disease.

Surprisingly, morphological changes consistent with diabetic nephropathy were found in three patients with gestational diabetes. Equally surprisingly, glucose tolerance was normal in one and merely impaired (World Health Organisation criteria) in the two others when tested six weeks after delivery. Hypertension persisted in two of these patients.

The eight cases of reflux nephropathy and the two of polycystic kidney disease found by intravenous pyelography had not been diagnosed before.

Essential hypertension was diagnosed in 21 patients $(25 \%)$ with early onset pre-eclampsia. Five of the 11 primiparas gave a history of hypertension when taking oral contraceptives. All 10 multiparas had had pre-eclampsia in past pregnancies, were hypertensive during the first trimester of the index pregnancy, and showed changes of hypertensive retinopathy consistent with longstanding disease.

Sixteen of the 94 patients with late onset pre-eclampsia (17\%) had chronic renal disease (table II). There were three with known reflux nephropathy and seven with diagnosed glomerulonephritis. The other six patients had glomerular haematuria; in four biopsy showed IgA nephropathy.

\section{Discussion}

Though only about half of the known patients who developed early onset pre-eclampsia were available for follow up evaluation, this study shows that the presence of a renal abnormality predisposing to pre-eclampsia was much more common in the early onset group both in primiparas and in multiparas. Not only were these patients suffering from a more severe form of pre-eclampsia compared with the late onset group but maternal morbidity (coagulopathy, more severe hypertension) and fetal mortality were

TABLE II-Aetiology of pre-eclampsia by time of onset in primiparas and multiparas. Figures are numbers (percentages) of patients

\begin{tabular}{lcccccccc}
\hline & \multicolumn{3}{c}{ Early onset } & & \multicolumn{3}{c}{ Late onset } \\
\cline { 2 - 4 } Final diagnosis & Primiparas & Multiparas & Total & & Primiparas & Multiparas & Total \\
\hline Renal disease & $33(67)$ & $22(63)$ & $55(65)$ & & $11(15)$ & $5(24)$ & $16(17)$ \\
Essential hypertension & $11(22)$ & $10(29)$ & $21(25)$ & & $5(7)$ & $12(57)$ & $17(18)$ \\
Idiopathic pre-eclampsia & $5(10)$ & $3(9)$ & $8(10)$ & & $57(78)$ & $4(19)$ & $61(65)$ \\
\hline Total & $49(100)$ & $35(100)$ & $84(100)$ & & $73(100)$ & $21(100)$ & $94(100)$ \\
\hline
\end{tabular}

Table III lists the medical disorders associated with early onset preeclampsia. All 45 patients with glomerulonephritis were submitted to renal biopsy and in each case there was appreciable glomerular haematuria (40$1500 \times 10^{6}$ dysmorphic erythrocytes per litre). IgA glomerulonephritis was the most common finding ( 25 cases $(56 \%)$ ), the next most common being non-IgA mesangial proliferative glomerulonephritis (14 cases (31\%)). All

TABLE III-Specific disorders associated with early onset pre-eclampsia in primiparas and multiparas

\begin{tabular}{lccc}
\hline & Primiparas & Multiparas & $\begin{array}{c}\text { Total } \\
(\text { No }(\%))\end{array}$ \\
\hline Glomerulonephritis: & 15 & 10 & $25(30)$ \\
IgA & 8 & 6 & $14(17)$ \\
Non-IgA & 2 & 1 & $3(4)$ \\
Systemic lupus erythematosus & 1 & 2 & $3(4)$ \\
Diabetic & 5 & 3 & $8(10)$ \\
Non-glomerular renal disease: & 2 & 0 & $2(2)$ \\
Reflux nephropathy & 11 & 10 & $21(25)$ \\
Polycystic kidneys & 5 & 3 & $8(10)$ \\
Essential hypertension & 59 & 35 & $84(100)$ \\
Idiopathic pre-eclampsia & 49 & & \\
\hline Total & &
\end{tabular}

also higher (table I). Pre-eclampsia was often preceded by low urinary oestriol excretion indicating impaired placental function. Impaired fetal growth before the onset of clinical signs of preeclampsia has been described. ${ }^{2}$

Mesangial IgA nephropathy was the most common form of glomerulonephritis associated with early onset pre-eclampsia ( 25 of 45 cases). IgA nephropathy is the most common form of nephritis in France, Japan, Singapore, and Australia with up to $1-2 \%$ of the population thought to have this disease. ${ }^{3}$ It is also the most frequent form of glomerulonephritis leading to end stage kidney disease in Australia. ${ }^{4} \operatorname{Ig} A$ nephropathy is a persistent form of glomerulonephritis and does not resolve spontaneously, despite normal urinary findings. ${ }^{56}$ It is therefore of paramount importance to diagnose and review these patients periodically, as progress of the disease is quite variable. ${ }^{6}$ Continuing heavy microscopic haematuria and persistent hypertension particularly point to a poor prognosis.

Patients with mesangial IgA nephropathy in pregnancy are far more likely to show segmental lesions of hyaline degeneration and sclerosis than are non-pregnant patients with this immune complex disease. ${ }^{7}$ As IgA nephropathy tends to progress by the formation of segmental lesions, pregnancy may accelerate the formation of this lesion. This was shown by one of our patients with recurrent early onset pre-eclampsia and appreciable deterioration in renal function 
(creatinine concentration $50-110 \mu \mathrm{mol} / 1 ; 0.6-1 \cdot 2 \mathrm{mg} / 100 \mathrm{ml}$ ) for whom histological findings were available before and immediately after the pregnancy.

In the early onset group eight of the 10 multiparas with IgA disease had suffered pre-eclampsia in previous pregnancies. After these earlier pregnancies they had become normotensive but phase contrast microscopy had not been performed. The presence of appreciable microscopic haematuria in subsequent pregnancies suggests that their previous episodes of pre-eclampsia were very likely related to IgA disease.

In 25 patients with IgA nephropathy 21 did not have appreciable proteinuria post partum and only five continued to be hypertensive, while renal function was normal in all. This emphasises that normal renal function and absence of proteinuria post partum do not exclude underlying renal disease in women with recurrent or early onset pre-eclampsia.

Not all patients with IgA nephropathy who become pregnant, however, are destined to develop pre-eclampsia. Our patients were selected because of problems related to pregnancy. Katz et al found a low incidence of pre-eclampsia in women with known kidney disease. ${ }^{8}$ Nevertheless, a previous study suggested that the presence of IgA nephropathy and pre-eclampsia has a high association, with $62 \%$ of pregnancies complicated by this condition.' Again, however, these patients were referred only because of problems related to pregnancy.

We were surprised by biopsy findings consistent with diabetic nephropathy in the three patients who had gestational diabetes, since one had required insulin during pregnancy to maintain normoglycaemia. Gonzalez-Gonzalez et al reported similar findings in eight women with mild diabetes in pregnancy, four of whom developed pre-eclampsia.' All eight had biopsy changes consistent with diabetic nephropathy.

This study has shown that a presumptive diagnosis of true or idiopathic pre-eclampsia is likely to be correct only in primiparas who develop the signs late in pregnancy. In all others a careful search for an underlying medical disorder has a high probability of yielding a positive finding, as shown by a $90 \%$ prevalence of causative disease (roughly two thirds renal) in this short term follow up investigation. Multiparous patients with pre-eclampsia (early or late) should also always be thoroughly investigated. Pre-eclampsia should not be taken as a final diagnosis. It is a pregnancy related syndrome only in the small group with a late onset (greater than 37 weeks of gestation).

Definitive diagnosis enables a more informed prognosis to be given for future pregnancies. Nevertheless, reliance on only biochemical indices of renal function in order to detect renal impairment will underestimate the presence of chronic renal disease; careful phase contrast microscopy should therefore be carried out, which is cheap and a very useful screening test with a high sensitivity and specificity and no false positivity. This simple test also allows confident selection of patients who might be considered for renal biopsy.

\section{References}

1 Fairley KF, Birch DF. Haematuria: a simple method for identifying glomerular bleeding. Kidney Int 1982;21:105-8.

2 Long PA, Abell DA, Reischer NA. Fetal growth and placental function assessed by urinary estriol excretion before the onset of pre-eclampsia. Am $\mathcal{O}$ Obstet Gynecol 1979;135:344-7.

$3 \mathrm{Lim}$ CH, Woo KT, Pwee HS, Edmonson RPS, Chaing GSC. The results of screening for proteinuria and microscopic haematuria on 16 year old national service registrants. In: Becker GJ, Atkins RC, Kincaid-Smith P, eds. Proceedings of 2nd Asian Pacific congress of nephrology. Maryborough: The Dominion Press-Hedges and Bell, 1984:175-82.

4 Disney APS, Sheil AGR, eds. Seventh report of the Australian and New Zealand combined dialysis and transplant registry. Woodville: Queen Elizabeth Hospital and Australian Kidney Foundation,
tisney APS, Sheil AGR, eds. Seventh report of the Australian and New Zealand combined dialysis and 1984.

5 Nicholls KM, Fairley KF, Dowling JP, Kincaid-Smith P. The clinical course of mesangial IgA associated nephropathy in adults. $Q \mathcal{F}$ Med 1984;210:227-50

6 Kincaid-Smith P. Mesangial IgA nephropathy. BrMed J 1985;290:96-7.

7 Kincaid-Smith PS, Whitworth J, Fairley KF. Mesangial IgA nephropathy in pregnancy. Clin Exp Hypertens 1980;2:821-38.

8 Katz AI, Davison JM, Hayslett JP, Singson E, Lindheimer MD. Pregnancy in women with kidney disease. Kidney Int 1980;18:192-200.

9 Gonzalez-Gonzalez L, Lopez-Llera M, Gonzalez-Angulo A, Linares GR, Sneider GB. Diabetes mellitus and toxemia of pregnancy: electron microscopic study of renal biopsies. $\mathcal{I}$ Reprod Med 1971;7:133-8.

(Accepted 8October 1986)

\title{
Life threatening sickle chest syndrome treated with extracorporeal membrane oxygenation
}

\author{
D S GILLETT, K E J GUNNING, E H SAWICKA， A J BELLINGHAM， R J WARE
}

\begin{abstract}
A young West Indian woman with established sickle cell disease developed a severe episode of sickle chest syndrome. Conventional treatment including exchange transfusions and mechanical ventilation was to no avail, and an infusion of epoprostenol also failed to halt her worsening condition. When her arterial oxygen tension $\left(\mathrm{PaO}_{2}\right)$ had fallen to $6.5 \mathrm{kPa}$
\end{abstract}

King's College Hospital, London SE5

D S GILLETT, MRCP, MRCPATH, lecturer and honorary senior registrar in haematology

K E J GUNNING, FRCS, FFARCS, registrar in anaesthesia

E H SAWICKA, MD, MRCP, senior registrar in thoracic medicine

A J BELLINGHAM, FRCP, professor of haematology

R J WARE, FFARCS, consultant anaesthetist and director of intensive care unit

Correspondence to: Dr Sawicka.
$(49 \mathrm{~mm} \mathrm{Hg}$ ) extracorporeal membrane oxygenation was instituted.

Within two days her $\mathrm{PaO}_{2}$ was greatly improved (maximum 11.6 $\mathrm{kPa} ; 87 \mathrm{~mm} \mathrm{Hg}$ ), and by the sixth day pulmonary vascular resistance was reduced and angiography showed reperfusion of many vessels. The patient recovered and six months later showed a transfer factor close to the predicted range and normal spirometric values.

Extracorporeal membrane oxygenation should be considered for severe sickle chest syndrome when conventional methods of artificial ventilation fail.

\section{Introduction}

Sickle chest syndrome is a common complication of sickle cell disease, presenting with chest pain, fever, and leucocytosis. The pathophysiology is uncertain, and some patients become progressively hypoxic and die despite conventional management and 